\begin{tabular}{cc} 
Sharif University of Technology \\
Scientia Iranica \\
SCIENTIA & Transactions B: Mechanical Engineering \\
I RAN I CA & \\
\hline
\end{tabular}

\title{
Hydroelastic analysis of surface piercing hydrofoil during initial water entry phase
}

\author{
N. Javanmardi and P. Ghadimi* \\ Department of Marine Technology, Amirkabir University of Technology, Hafez Ave., No. 424, Tehran, P.O. Box 15875-4413, Iran.
}

Received 7 November 2016; received in revised form 7 October 2017; accepted 11 December 2017

\section{KEYWORDS}

Surface piercing

hydrofoil;

Oblique water entry;

Hydroelastic analysis;

Characteristic curves.

\begin{abstract}
In the current paper, numerical simulations of Fluid Structure Interaction (FSI) of a SP (Surface Piercing) hydrofoil are conducted in order to study the influence of elasticity on the initial water entry ventilation. Using ANSYS multi physics solvers, twoway FSI analyses are conducted by the implicit coupling of URANS (Unsteady Reynolds Averaged Navier-Stokes) equations with a finite-element method. Numerical results are validated by the well-known rigid and elastic wedge water entry problems. Subsequently, computational results are presented for ranges of different velocity ratios $(0.38,0.64)$ and elasticity factor $[0,4]$. Similar to the Surface Piercing Propeller (SPP), performance curves of a wedge water entry are defined. The obtained similar trend of propeller and wedge performance curves in fully ventilated, transition, and partially cavitated operation modes shows that the adopted approach (2D-study) can be appropriate for future related studies. FSI simulation results indicate that structural deformation can highly affect the location of transition point and shift it toward the fully ventilated part at high Froude number and elasticity factor. The overall efficiency loss due to the increase of foil elasticity is observed, and overshoot time of the foil deformation related to the variation of Froude number and elasticity factor is evaluated.

(C) 2019 Sharif University of Technology. All rights reserved.
\end{abstract}

\section{Introduction}

\subsection{Surface piercing propeller characteristics}

Surface piecing propellers are well-known propulsors for their appropriate performance in variable submergence. Design of these propulsors requires a precise estimation of hydrodynamic forces, moments, and resulting stresses and strains. The impact hydrodynamic forces due to water entry and water exit of each blade are still considered as the challenge of designing the SPPs. As a result, proper hydroelastic analysis of

\footnotetext{
*. Corresponding author. Tel.: +982164543110; Fax: +982166412495

E-mail addresses: n.javan@aut.ac.ir (N. Javanmardi); pghadimi@aut.ac.ir (P. Ghadimi).
}

doi: $10.24200 /$ sci. 2017.20010 water entry process is imperative for a wide range of researches involving experiments and CFD modelling.

Hadler and Heker [1] and Hecker [2] initially identified hydrodynamic characteristic curves of a partially submerged propeller. They conducted experimental measurements on Surface Piercing (SP) hydrofoils and SPPs. They first introduced three main free surface patterns of fully ventilated, transition, and partially cavitated. Later on, Brandt [3] experimentally developed the primary performance curves of the SPPs. On the other hand, Oloffson's studies [4,5] focused on transient behavior of forces and torque of a blade during a rotation. The experimentally recorded forces on a single blade showed that an abrupt increase in hydrodynamic force is observed when the single blade impacts the water.

Young and Kinnas [6,7], on the other hand, studied the hydroelastic performance of SPPs through 
another approach. Using the coupled BEM (Boundary Element Method) and FEM methods, they investigated the hydroelastic behavior of a propeller in a steady condition. The negative image method was applied to model the involved free surface. Gravity effects were ignored, implying that simulations were conducted for Froude number approaching infinity. Meanwhile, Young [8] developed a computer code for analyzing the composite NACA foil propeller's hydrodynamics characteristics, later used by Young and Savander [9] to study the transient hydroelastic response of the stainless steel SPPs. In order to determine more accurate transient structural behavior of the SPP blade [8], in addition to pressure distribution, the obtained added mass and damping matrices of fluid part were utilized, too. However, for the investigated SPP, due to the small deflection of that particular blade, they did not offer any significant FSI effects or ventilation pattern change. Moreover, the composite submerged NACA foil propeller showed notable deflection, which caused a decrease in propeller load and an increase in efficiency. Using the 1-way coupled URANS and FEM methods, Javanmardi and Ghadimi [10] studied the hydroelastic behavior of a five-blade SPP. The gravity, cavitation, and fluid viscosity were considered. The obtained results revealed that, for an isotropic material, the SP blades bend toward the propeller shaft and twist in a way that blade pitch angle increases. Moreover, blade's thin leading edge was seen to deform considerably more than the thick trailing edge (Figure 5). However, the one-way coupling simulation could not show the fluid and structural interactions, realistically.

\subsection{D wedge water entry characteristics}

3D numerical simulation of a semi-submerged highspeed propeller involves computational complexity and high cost. On the contrary, 2D simulation of the blade section can furnish more information about the propeller performance and is also computationally efficient. Through 2D simulation conductance, the theoretical models of Wagner [11] and Von Karman [12] for the wedge water entry can also be utilized for the blade section. These methods have been introduced based on the added mass concept for the potential flow. Yim [13] was the first to present a 2D analytical method for simulation of fully ventilated water entry and exit of a thin infinite symmetric wedge based on Wagner theory [11]. Vinayan and Kinnas [14] prepared a 2D BEM code to consider the nonlinear nature of the free surface pattern. He investigated the symmetric oblique wedge studied by Cox [15] and provided the pressure curves and free surface patterns. However, based on a comparison of URANS-based simulations of Ghadimi et al. [16-18] with the analytical method proposed by Ghadimi et al. [19], SPH simulations by Farsi and Ghadimi [20-22], and the conducted study by
Feizi Chekab et al. [23], the effects of fluid viscosity on modelling the arbitrary object's water entry improve the accuracy of water impact characteristics.

Faltinsen $[24,25]$ was the first to present theoretical and experimental studies regarding the water entry of the elastic wedge shape panel. He had a significant role in the recognition of the importance of hydroelastic issue in a maritime research field. He introduced hydroelastic analysis by the one-way coupling of orthotropic plate theory with Laplace equation as the governing equation of the fluid part. Through this method, structural stress and strain of the water-entering wedge with the reinforced plate were simulated. These studies indicated that an increase in the impact velocity as well as the reduction of wedge deadrise angle could strongly increase the plat strain and deformation. To examine the importance of the elasticity effect on the fluid hydrodynamic characteristics, he introduced the "hydroelasticity factor", which is the combination of the fluid viscosity, wedge geometry, and material characteristics.

The water entry model in a hydroelastic problem, extensively studied, is related to moderate deadrise angle wedge with a simply supported walls side (Figure 9 ). This well-known model is used for validation purposes in the current paper. Lu et al. [26] utilized the coupled BEM method and plate theory to simulate water entry process of the mentioned wedge. His investigations showed that a reduction in plate thickness increases the elasticity effects. He also suggested that, for the reduction of the plate thickness, the usage of the twoway coupled solver is inevitable. Korobkin et al. [27] compared the accuracy and computational cost of two methods to simulate water entry problem of $\mathrm{Lu}$ et al. [26]. He coupled the Wagner analytical method with (a) direct FEM to simulate the water entry part and (b) modal analysis for the structural simulation. As a result, he concluded that the modal analysis method has acceptable accuracy and low computational cost in most of the usual cases.

Maki et al. [28] and Dominic et al. [29] utilized one- and two-way coupling of URANS (Unsteady Reynolds Averaged Navier-Stokes) equations with elastic beam theory to simulate the elastic wedge water entry with constant and variable impact speeds. They employed Finite-Volume Method (FVM) based Open FOAM solver to model the fluid part and FEM program to model the structural part. It was concluded that one-way coupling has acceptable results only for hydroelastic problem of small structural deformations.

Depending on the value of flow attack angle, an elastic SP hydrofoil water entry has different ventilation patterns in the presence of water, air, and vapor phases. However, most of the hydroelastic analyses of the wedge have been conducted for moderate deadrise angle geometry without the presence of water horizon- 
tal velocity. The ventilation mechanism at the transition point plays an essential role in the characteristic curves of SPPs, and any change and deflection in the blade geometry can affect this point's specifics. Based on the literature, for an isotropic material, the blade twists toward increasing pitch angle, which can affect the trend of ventilation pattern during the blade water entry. This issue has not been considered yet.

In the current study, using the advantage of $2 \mathrm{D}$ low cost simulation, instead of a 3D complicated approach, the two-way coupled simulation of unsteady ventilating-cavitating turbulent flow around $2 \mathrm{D}$ elastic surface piercing hydrofoils is conducted in initial water entry phase. To this end, the direct FEM method is employed in structural simulation parts, and URANS equations are applied as the governing equations of the turbulent flow. Free surface shape and ventilation patterns are extracted by coupling the URANS with volume of fluid technique. Ansys-CFX and ansysmechanical commercial software products are employed as fluid and structure solvers, respectively. To ascertain the influence of foil elasticity on the performance curves of surface piercing hydrofoil, different simulations are conducted with respect to a range of elasticity modules and attack angles. Furthermore, free surface patterns, pressure distribution, performance curves, and unsteady behavior of the foil deflections are investigated in the current paper.

\section{Governing equation}

\subsection{Viscous unsteady flow governing equations}

Based on the conducted literature review, the URANS equations are considered as the governing equations to model a more realistic situation for the hydrodynamic part. Since the present study deals with three different phases of vapor, water, and air, the mixture is assumed homogeneous. Accordingly, momentum URANS equations are utilized in a general form in terms of mixture's pressure, velocity, and viscosity as in the following:

$$
\begin{gathered}
\frac{\partial\left(\rho_{m} \bar{v}_{i}\right)}{\partial t}+\frac{\partial\left(\rho_{m} \bar{v}_{i} \bar{v}_{j}\right)}{\partial x_{j}}=\rho_{m} \bar{f}_{i}-\frac{\partial P}{\partial x_{i}}+\frac{\partial \tau_{i j}}{\partial x_{j}} \\
\tau_{i j}=\mu_{m}\left(\frac{\partial \bar{v}_{i}}{\partial x_{j}}+\frac{\partial \bar{v}_{j}}{\partial x_{i}}-\frac{2}{3} \frac{\partial \bar{v}_{k}}{\partial x_{k}} \delta_{i j}\right)-\rho_{m} \overline{v_{l}^{\prime} v_{J}^{\prime}}
\end{gathered}
$$

where $P$ and $\bar{v}_{i}$ are the time-averaged pressure and velocity components, respectively; $\bar{f}_{i}$ is average body force component; $\delta_{i j}$ is the unit tensor; and $\tau_{i j}$ is the shear stress tensor. Also $-\rho_{m} \overline{v_{l}^{\prime} v_{J}^{\prime}}$ refers to the Reynolds stresses representing the turbulence fluctuations in fluid momentum requiring to be modelled. SST $k-\omega$ turbulent model is utilized to improve the prediction of pressure gradients near the wall as well as that of flow separation near the leading edge of SP hydrofoil. Also $\mu_{m}$ and $\rho_{m}$ are the mixture's viscosity and density, respectively, and can be written in the following fractional form:

$$
\begin{aligned}
& \rho_{m}=\alpha_{a} \rho_{a}+\alpha_{w} \rho_{w}+\alpha_{v} \rho_{v}, \\
& \mu_{m}=\alpha_{a} \mu_{a}+\alpha_{w} \mu_{w}+\alpha_{v} \mu_{v} .
\end{aligned}
$$

In Eq. (3), $\rho_{a}^{\prime}, \rho_{w}$ and $\rho_{v}$ are air, water, and vapor density, respectively. Similarly, $\mu_{a}, \mu_{w}$, and $\mu_{v}$ are air, water, and vapor dynamic viscosity, respectively. In addition, $\alpha_{a}$ is air volume fraction, $\alpha_{w}$ is water volume fraction, and $\alpha_{v}$ is vapor volume fraction in a cell to be used in the VOF method and is known as follows:

$$
\alpha_{a}+\alpha_{w}+\alpha_{v}=1 \text {. }
$$

The VOF method focuses on the tracking of the interface between two or more phases of the flow with sharp interfaces, such as free-surface flows, suitable for the flow pattern in the current paper. Continuity equation of the mixture can be presented based on the vapor, air, and water fractions. These equations include:

$$
\begin{aligned}
& \frac{\partial\left(\alpha_{a} \rho_{a}\right)}{\partial t}+\nabla \cdot\left(\alpha_{a} \rho_{a} \bar{v}^{\prime}\right)=0, \\
& \frac{\partial \alpha_{w}}{\partial t}+\nabla \cdot\left(\alpha_{w} \bar{v}^{\prime}\right)=-\dot{m} / \rho_{w}, \\
& \frac{\partial\left(\alpha_{v} \rho_{v}\right)}{\partial t}+\nabla \cdot\left(\alpha_{v} \rho_{v} \bar{v}^{\prime}\right)=\dot{m},
\end{aligned}
$$

where subscripts $a, v$, and $w$ denote air, vapor, and water fluid, respectively; $(\dot{m})$ is the mass transfer rate that is only observed between water and vapor phases. Based on the favorable results of Bagheri et al. [30], in simulation of the propeller cavitation using the evaporation and condensation equation of Zwart model [31], these equations are also used in the current paper to extract the mass transfer rate value. These equations include:

$$
\begin{aligned}
\dot{m}= & \dot{m}_{e}-\dot{m}_{c}, \\
\dot{m}_{e}= & C_{e} \frac{3\left(1-\alpha_{v}\right) \alpha_{n u c} \rho_{v}}{R_{b}} \\
& \sqrt{2\left(P_{v}-P_{o}\right) / 3 \rho_{w}} \operatorname{sign}\left(P_{v}-P_{o}\right), \\
\dot{m}_{c}= & C_{c} \frac{3 \alpha_{v} \rho_{v}}{R_{b}} \sqrt{2\left(P_{o}-P_{v}\right) / 3 \rho_{w}} \operatorname{sign}\left(P_{o}-P_{v}\right),
\end{aligned}
$$

where $C_{e}$ and $C_{c}$ are empirical values equal to 50 and 0.01 , respectively; $R_{b}$ is the mean radius of the bubble and is assumed to be $1 \times 10^{-6} \mathrm{~m}$, as proposed by Ji [32]; and $\alpha_{n u c}$ is the vapor fraction which is considered to be $5 \times 10^{-4}$, as proposed by Mejri [33]. 


\subsection{Structure governing equations}

FSI simulation of the water entry problem has a transient nature in fluid loads and structural displacements. Therefore, to simulate the structural behavior including inertia and damping effect, the dynamic finiteelement formulation based on dynamic equilibrium is required. Since the structural deformation is considered in linear deformation range, the stable implicit transient FEM scheme, defined by Newmark's [34] time integration methods, which is available in ANSYS, can be used. The semi-discrete form of the motion equation can be rewritten as follows:

$$
[M]\left\{\ddot{u}_{n+1}\right\}+[C]\left\{\dot{u}_{n+1}\right\}+[K]\left\{u_{n+1}\right\}=\left\{F_{n+1}\right\},
$$

where $[M]$ is mass matrix, $[C]$ is damping matrix, $[K]$ is stiffness matrix, $\{F\}$ is load vector, and $\{\ddot{u}\},\{\dot{u}\}$, and $\{u\}$ are nodal acceleration, velocity, and displacement vector, respectively. Indices $n$ and $n+1$ are related to the vectors at times $t_{n}$ and $t_{(n+1)}$. With three known values of $\left\{u_{n}\right\},\left\{\dot{u}_{n}\right\}$, and $\left\{\ddot{u}_{n}\right\}$, the three unknowns $\left\{u_{n+1}\right\},\left\{\dot{u}_{n+1}\right\}$, and $\left\{\ddot{u}_{n+1}\right\}$ maybe calculated by the three algebraic equations defined by Newmark [34] integration algorithms, which are:

$$
\begin{aligned}
\left(a_{0}[M]\right. & +a_{1}[C]+[K]\left\{u_{n+1}\right\}=\left\{F_{n+1}\right\} \\
& +[M]\left(a_{0}\left\{u_{n}\right\}+a_{2}\left\{\dot{u}_{n}\right\}+a_{3}\left\{\ddot{u}_{n}\right\}\right) \\
& +[C]\left(a_{1}\left\{u_{n}\right\}+a_{4}\left\{\dot{u}_{n}\right\}+a_{5}\left\{\ddot{u}_{n}\right\}\right), \\
\left\{\dot{u}_{n+1}\right\} & =a_{1}\left(\left\{u_{n+1}\right\}-\left\{u_{n}\right\}\right)-a_{4}\left\{\dot{u}_{n}\right\}-a_{5}\left\{\ddot{u}_{n}\right\}, \\
\left\{\dot{u}_{n+1}\right\} & =a_{0}\left(\left\{u_{n+1}\right\}-\left\{u_{n}\right\}\right)-a_{2}\left\{\dot{u}_{n}\right\}-a_{3}\left\{\ddot{u}_{n}\right\} .
\end{aligned}
$$

The value of $a_{0}$ to $a_{5}$ can be set by Newmark's integration formulation as in [34].

\subsection{FSI solution method and interface boundary conditions}

There are two main approaches to solving the FSI equations: Monolithic and partitioned approaches. In the monolithic or direct approach, one solver is used to solve a combined large matrix of flow and solid, while, in the partitioned approach, two different domains are solved by two distinct solvers, which can communicate implicitly or explicitly. Therefore, flow or structural equations' codes and efficient solution techniques maybe considered, separately. In this paper, due to the complex flow conditions and limited structural deformation, the strongly coupled (implicit) partitioned approach, available in ANSYS multi-field solver, is implemented. A sequential solution of flow and solid parts is shown in a flowchart scheme shown in Figure 1.

Generally, in FSI problems, two types of data of load and displacement should be transferred through the solid-fluid interface boundary. The resultant force on the interface of the wedge $\left(F_{i}\right)$ for the structure and fluid domain will be equal and is given as follows:

$$
F_{i}=\int_{A_{s}} \sigma_{i j} n_{j} d A_{s}=-\int_{A_{f}}\left(-P \delta_{i j}+\tau_{i j}\right) n_{j} d A_{f},
$$

where $A_{s}$ and $A_{f}$ are the interface area on the structure and fluid side, respectively; $\sigma_{i j}$ is the structural stress tensor on the interface cells; and $n_{j}$ is the normal vector in $j$ direction. Since the transferred load from the fluid to solid domain is globally conservative, it is transferred subsequently by a conservative data capturing method (GGI method in ANSYS). On the other hand, since the profile of the structural walls displacement should

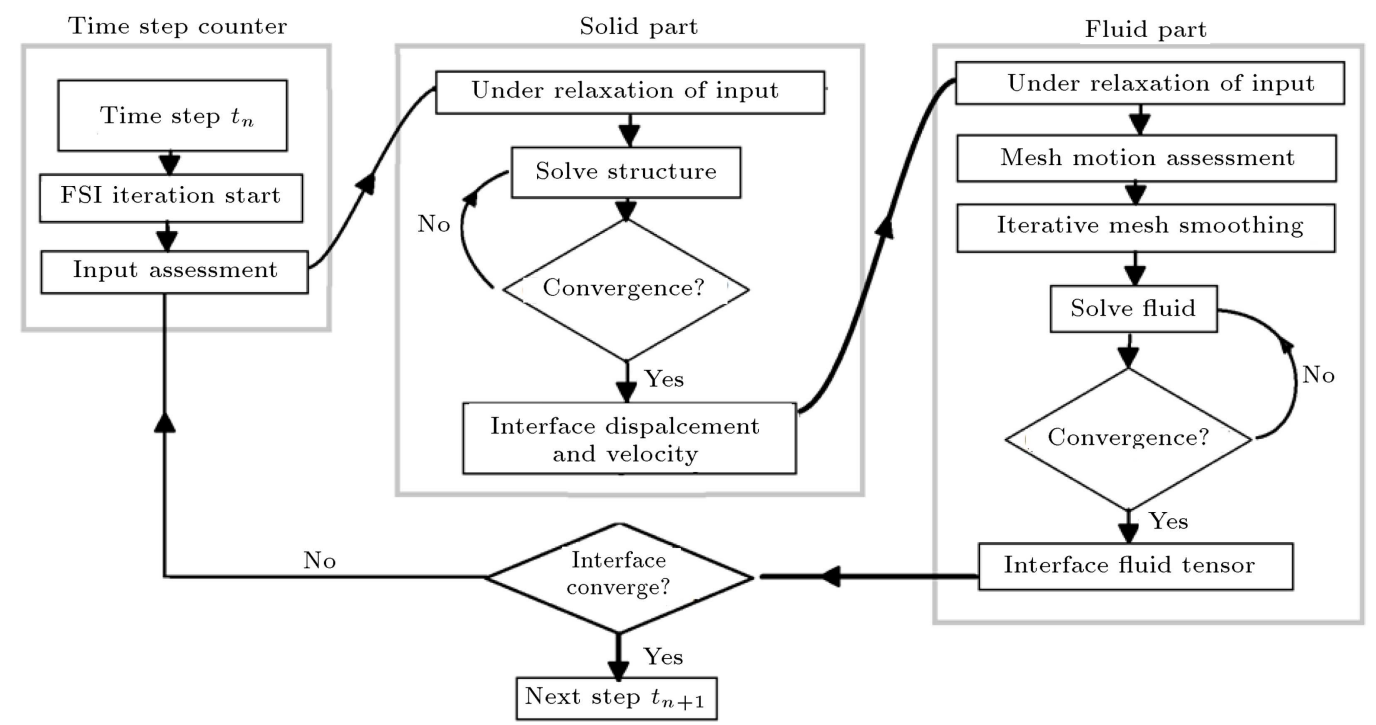

Figure 1. Sequential solution of flow and solid parts flowchart. 
be preserved during iterative data transferring, the profile preserving method is implemented to transfer the wedge deformation. As a result, for the synchronization points of both domains, the fluid and solid displacement and, thus, the wall velocity are the same, meaning that:

$$
\overrightarrow{u_{f}}=\overrightarrow{u_{s}}, \overrightarrow{u_{s}}=\vec{v}
$$

Herein, $\overrightarrow{u_{f}}$ and $\overrightarrow{u_{s}}$ are the fluid and structure deformation vector, while, $\overrightarrow{\vec{u}}_{s}$ and $\vec{v}$ are, respectively, the structure and fluid velocity at the fluid and structure interface.

\section{Problem and parameters definition}

\subsection{Parameters' definition}

To investigate the hydrodynamic behavior of the initial water entry process of the SPPs, the geometry of the wedge-shaped hydrofoil is extracted from a section of 821-b surface piercing propeller. In the current paper, the section of this propeller at 0.55 of blade radius is investigated. The combined principal parameters of the propeller and a water-entering wedge used in this paper, which are advance coefficient $J$, velocity ratio $\varepsilon$, and Froude and Cavitation numbers, are, respectively, determined using equations:

$$
\begin{aligned}
& J=U / n D, \\
& V=0.55 \pi n D \\
& \varepsilon=U / V=J / 0.55 \pi, \\
& F n=U / \sqrt{g D}, \\
& \sigma_{n}=\left(P_{a t m}-P v\right) / 0.5 \rho_{w} U^{2} .
\end{aligned}
$$

In these equations, $D, n, U, V, \rho_{w}$, and $P_{a t m}$ denote the propeller diameter, shaft speed, water advance speed, foil vertical speed, water density, and ambient pressure, respectively. The geometry of the considered SPP's wedge-shaped hydrofoil is illustrated in Figure 2.

In addition to the principal parameters, other dependent parameters reflect the hydrodynamic performance of the wedge water entry. These parameters

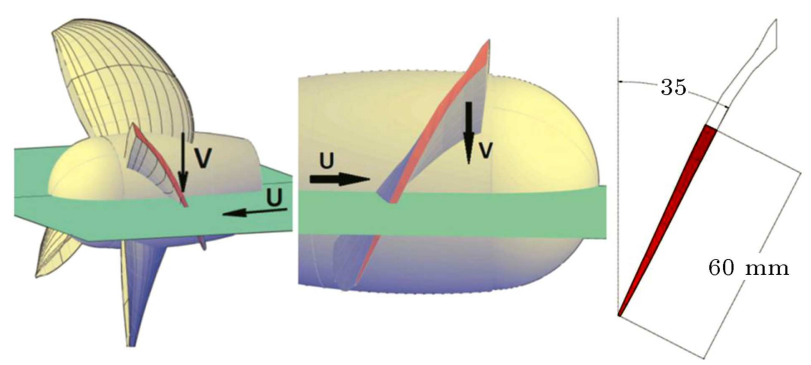

Figure 2. The extracted hydrofoil section from SPP propeller 821-b@ $0.55 \times$ propeller radius. include the pressure coefficient, vertical and horizontal forces, and efficiency coefficient. These parameters are, respectively, determined using equations:

$$
\begin{aligned}
& C_{P}=\left(P-P_{a t m}\right) / 0.5 \rho_{w} V^{2}, \\
& K_{F}=F / 0.5 \rho_{w} V^{2} V t, \\
& \eta_{\text {wedge }}=F_{x} U / F_{y} V,
\end{aligned}
$$

where $K_{F}$ represents the dimensionless form of forces $F_{x}$ and $F_{y}$. Wedge efficiency is defined similar to the propeller efficiency expression $\left(\eta_{\text {wedge }}\right)$. Hydrofoil added mass, $m^{\prime}$, in the initial water entry phase based on Von Karman theory could be estimated by:

$$
m^{\prime}=0.5 \rho \pi V^{2} t^{2} .
$$

In this paper, the flexibility of the hydrofoil changes through variation of elasticity modulus. The elasticity factor " $e$ " shows the flexibility ratio of hydrofoil structure related to steel material and it is defined by:

$$
e=E_{s} / E
$$

where $E_{s}=210 \mathrm{GPa}$ is the steel elasticity modulus, and $E$ is the hydrofoil material elasticity modulus. During hydrofoil penetration time, $t$, maximum foil deflection, $r^{\prime}$, occurs at leading edge for corresponding time, $t$. The dimensionless form of these parameters is:

$$
\begin{aligned}
& r^{*}=r^{\prime} E / \rho_{w} V^{3} t, \\
& t^{*}=V t^{\prime} / c
\end{aligned}
$$

where $r^{*}$ and $t^{*}$ are dimensionless deflection and time, respectively. Also, $E$ and $c$ are the hydrofoil structural elasticity modulus and chord length.

\subsection{Definition of ventilation pattern}

Water entry characteristics of SPPs and SP hydrofoils represent the variations of velocity ratio, $\varepsilon$ (or attack angle). As a result, depending on the value of velocity ratio, three different ventilation patterns may be observed. Trend of SPPs characteristic curves also depends on the location at which the patterns change. Therefore, a schematic form of these patterns and their effects on SPPs characteristic curves is displayed in Figure 3. The first ventilation pattern is called a fully ventilated mode in which water surface separates from the hydrofoil leading edge; consequently, ventilated cavity is formed on the foil's suction side (Figure 3(a)). In this condition, the fluid behavior is perfectly steady and the hydrodynamic pressure only acts on the pressure side. With respect to constant water inlet velocity, $U$, if impact velocity, $V$, decreases (lower attack angle), another condition is observed 

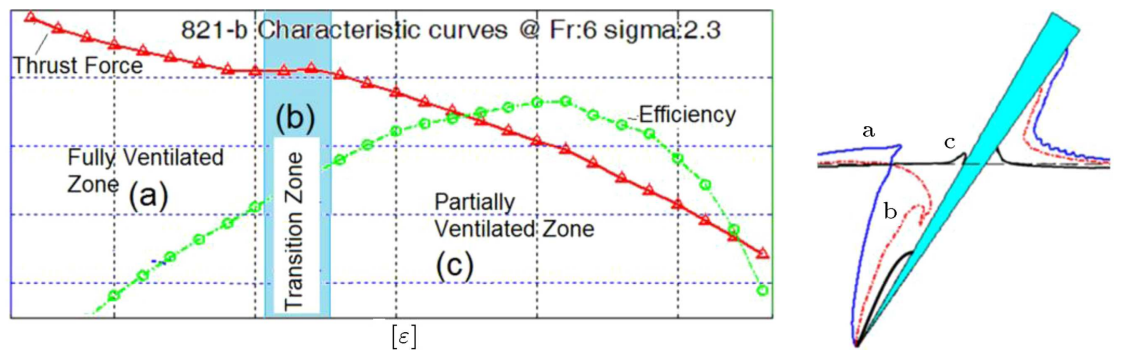

Figure 3. Dimensionless force and efficiency trend of 821-b propeller versus velocity ratio (left) and three types of ventilation patterns (right).

which is called transition mode (Figure $3(\mathrm{~b})$ ). In such a situation, the wall of air cavity starts to impact the foil body; as a result, the cavity is disconnected from the atmosphere. Meanwhile, the pressure does not display steady behavior and is highly affected by the variation of velocity ratio. The dimensionless forces increase when the pressure loss occurs in the disconnected cavity on the suction side. As the impact velocity continues to decrease, the third condition called partially ventilated or cavitated mode occurs in which the stable limited cavitation sheet begins from the leading edge on the foil suction side. As a result, a partially ventilation pattern is observed on the free surface (Figure 3(c)).

\section{Computational procedure setup}

In the current study, the geometry of a wedge-shaped SP hydrofoil with a left deadrise angle of $120.2^{\circ}$ and a right deadrise angle of $55^{\circ}$ is considered as a blade's section, as shown in Figure 4(a). Based on the designated deadrise angles, the pitch angle is determined to be $35^{\circ}$. The wedge is situated in a rectangular computational domain containing water and air separated by a free surface at a specific height. Initially, the wedge touches the undistributed free surface at a single point and starts to move down with a constant velocity, $V$. The computational domain is illustrated in Figure 4(b).

Similar to the propeller operational condition, the incoming flow of constant velocity $(U)$ enters from the upstream boundary location. Based on the Olofsson experiments [5], numerical simulation in the current paper is conducted in full-scale condition for two Froude numbers of 4 and 6 corresponding to input velocity of 6.26 and $9.39 \mathrm{~m} / \mathrm{s}$, respectively. To investigate the effect of elasticity on hydrodynamic characteristics of the wedge water entry, different flow angles of attacks are studied through variations of vertical blade speed, $V$. By considering the gravity effects, the distribution of initial hydrostatic pressure is implemented based on the water depth. Dimensions of the computational domain are selected based on the work of Shademani and Ghadimi [35] and Ghadimi et al. [36]. The upper and lower boundaries of the fluid domain are set as the constant static pressure and velocity inlet conditions, respectively (Figure 4(b)). Downstream location of the computational domain is defined to be an outflow patch, while "no-slip" and force/displacement interface conditions are set for the wedge's walls.

The results of the one-way FSI simulation by Javanmardi and Ghadimi [10] can be used to determine the structural support definition. Based on the obtained results, different deformation patterns, shown in Figure 5 , can be detected during the blade submergence process. At the initial phase of the blade water entry, the most notable deformation is the leading edge deflection (Figure 6(a)), and as the blade goes down deeper, the structural twisting is added to the deformation patterns (Figure 6(b)). Accordingly, while the blade is submerged completely, the distribution of the load over the blade area causes the overall bending deflection toward the upstream flow (Figure 6(c)).

Since the ventilation regimes are highly dependent on the formed profile of the free surface at the initial water entry phase process, this paper aims to investigate the variation of these regimes due to the
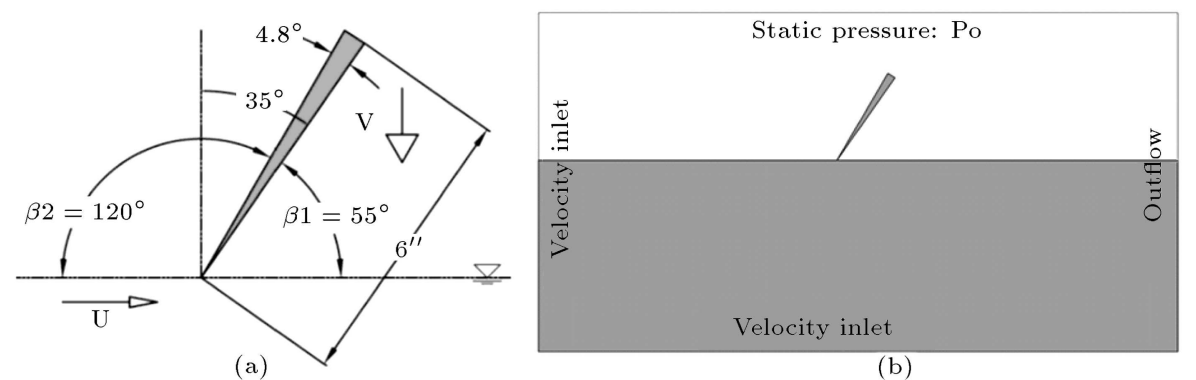

(b)

Figure 4. (a) The considered wedge geometry. (b) The considered computational domain boundary condition. 


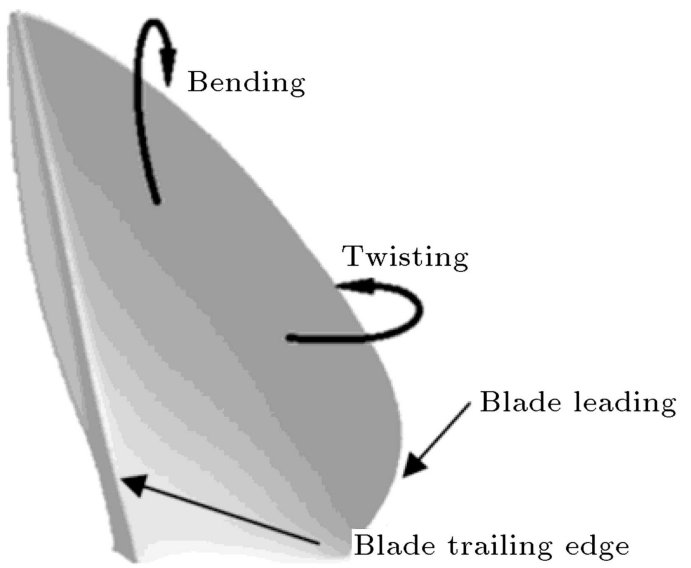

Figure 5. Schematic deflection of a SP blade [10].

structural deformations at initial water entry phases, as shown in Figure 6(a). As a result, the deflection of the thick trailing edge of the hydrofoil is assumed negligible in comparison with the thin leading edge, and the cantilever beam condition is prescribed on the trailing edge side (Figure 6(right)).

Through adjustment of the Courant number below unity, the time step for each blade velocity is prescribed based on the vertical displacement step, defined by $d_{y}=h / k$. Parameter $h$ is the oblique wedge height and $k$ is the number of divisions of the wedge height. The effect of displacement step is assessed by assuming $k=40,60,120,240$, and 480. Based on the comparison of the obtained vertical forces on the hydrofoil, it is found that $k=120$ is appropriate for rigid body simulation and decreasing the displacement step from $k=120$ to 480 slightly affects the computed forces by no more than $0.5 \%$. However, in the presence of elasticity and in order to avoid the negative volume fault, the $k=480\left(d_{y} \sim 0.1 \mathrm{~mm}\right)$ satisfies the remeshing iterative procedure.

Boundary layer mesh type is applied onto the wedge sides to improve the accuracy of the predicted wall function parameters, and structured mesh parallel to the undistributed free surface level is used for the remaining parts of the considered domain. It should be noted that the aspect ratio of the cells near the wedge's wall should be low enough to avoid a negative volume fault.

The effects of mesh size on the solution are investigated by considering four different meshing options of 0.4 [14], 0.5, 0.6, and 0.7 million cells. It is shown that increasing the cell numbers beyond 0.5 million has less than $1 \%$ effect on the resultant forces. However, to avoid a negative volume fault, the low aspect ratio cells near the wedge walls are utilized; consequently, the mesh option of 0.7 million cells is adopted for the current study. A schematic of the generated mesh is illustrated in Figure 7.

One thousand cells with a structural element type SOLID185 are used to mesh the structural domain. To apply the displacement of the nodes and to preserve the relative mesh distribution of the initial mesh, especially boundary layers mesh, the 'Displacement Diffusion'

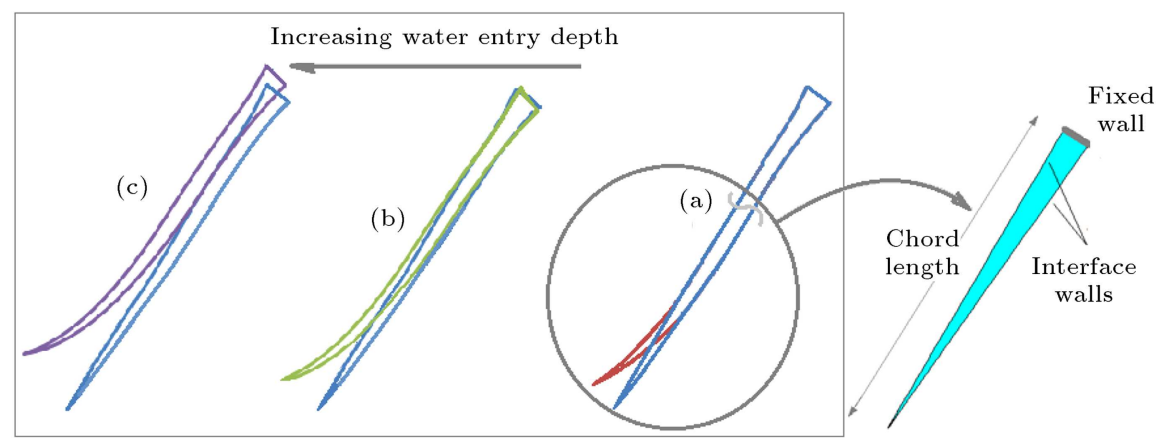

Figure 6. (Left) Schematic deflection patterns of a SP blade section during free surface penetration. (Right) Hydrofoil walls boundary condition.

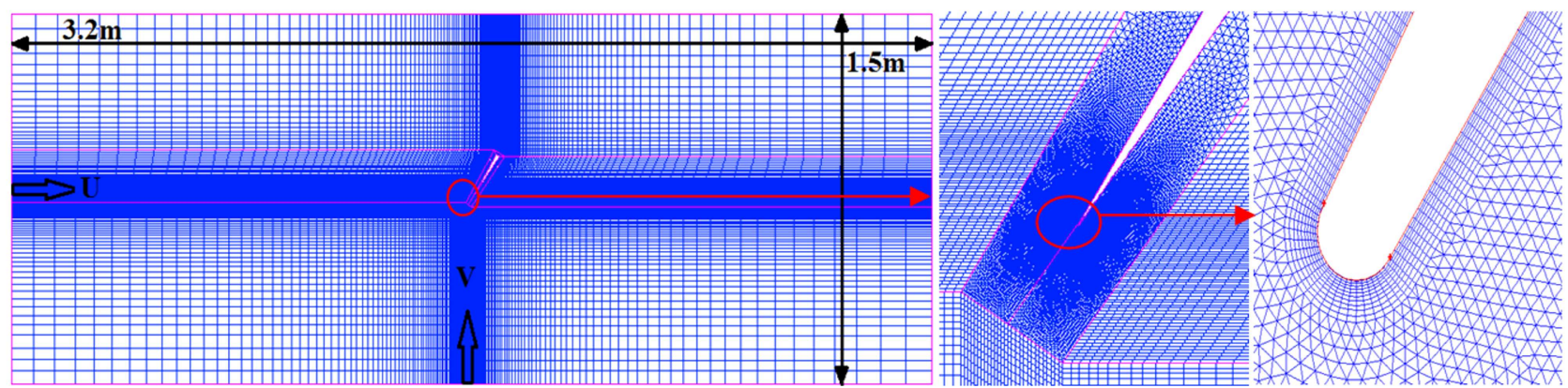

Figure 7. Illustration of the generated mesh. 
Table 1. Internal iteration loop number.

\begin{tabular}{cc}
\hline Iteration loop name & $\begin{array}{c}\text { Iterations no. at } \\
\text { each time step }\end{array}$ \\
\hline Mesh smoothing & 5 \\
FSI coupling loop & 10 \\
CFD loop & 10 \\
\hline
\end{tabular}

method is used to determine all domain nodes displacement [37]. This model diffuses the displacement of boundary nodes to other domain nodes by solving the equation:

$$
\nabla \cdot\left(\Gamma_{\text {disp }} \nabla \delta\right)=0,
$$

where $\Gamma$ and $\delta$ denote the mesh stiffness and the node displacement relative to the previous mesh locations, respectively [37]. Since the current problem involves three different phases, the mass transfer terms are determined using high-resolution advection schemes. To approximate fluid pressure and velocity, the secondorder Euler method is utilized. Based on the numerical solution flowchart (Figure 1), the transiently conducted numerical solution contains three parts of numerical iterations including mesh smoothing iterations, CFD loop iterations, and FSI coupling iterations. Each iteration loop number is set as shown in Table 1.

\section{Validation}

Two types of validations related to the paper concept are presented. The first validation case is related to the water entry simulation of the rigid thin wedge, and the second one is related to the flexible water-entering wedge.

\subsection{Rigid wedge water entry}

The experiment by Cox [15] was conducted on the symmetric solid wedge with dimensions shown in Figure $8(\mathrm{a})$ in the initial calm water condition. The wedge enters the initial calm water with a constant speed of $2.45 \mathrm{~m} / \mathrm{s}$. The free surface profile is investigated for incident angles $(\alpha)$ of 10 degrees. The obtained free surface profiles are compared with the results of Cox experiment [15] in Figure 8(b). In addition, the obtained pressure distribution for the mentioned wedge is compared with Vinayan's BEM results [14] in Figure 8(c).

As evident in the free surface comparison, there is favorable agreement between the free surface profiles on wedge's pressure side; besides, the difference of profiles on the suction side is in an acceptable state (Figure $8(\mathrm{~b}))$, and the computed pressure coefficient, $C_{p}$, shown in Figure 8(right), matches well with the results of BEM simulation done by Vinayan [14].

\subsection{Flexible wedge water entry}

To validate the proposed FSI simulation method, the reported elastic wedge water entry problem, investigated by Korobkin et al. [27] and Dominic et al. [29], is considered in this section. The schematic of the wedge and simulation domain are shown in Figure $9(\mathrm{a})$. The problem involves the water entry of a wedge whose length is $L=0.5 \mathrm{~m}$ and consists of a pinned-pinned beam with $18 \mathrm{~mm}$ thickness, $\gamma=10^{\circ}$, and deadrise angle, which impact the free surface with a constant vertical speed of $V=4 \mathrm{~m} / \mathrm{s}$.

The wedge material is steel with the elasticity modulus of $E=210 \mathrm{GPa}$. The symmetric condition of the domain can reduce the computations cost considerably. The dimensionless normal deformation at the middle of the beam during dimensionless time penetration, $V t / H$ (Figure $9(\mathrm{~b})$ ), is considered as a validation parameter. Hence, by utilizing 0.4 million cells in fluid domain and 500 cells in the structural domain, good agreement is achieved between the obtained deformation and analytical result of Korobkin et al. [27] and numerical data of Dominic et al. [29].

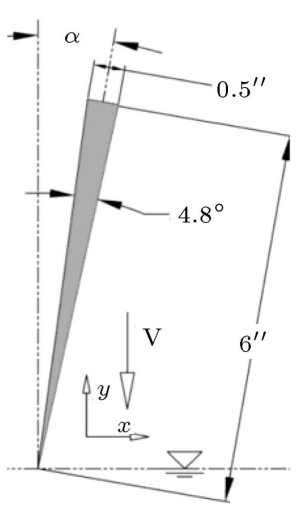

(a)

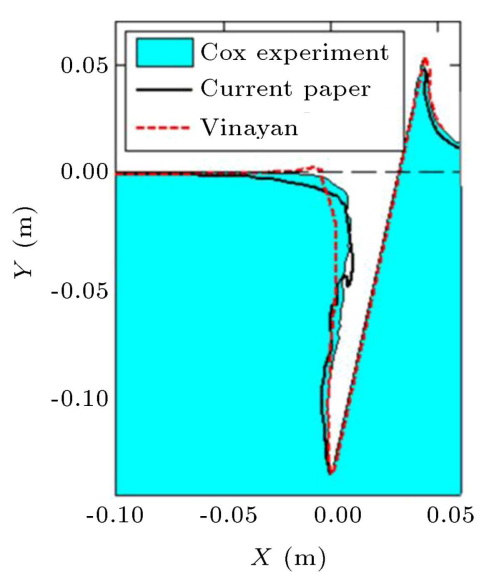

(b)

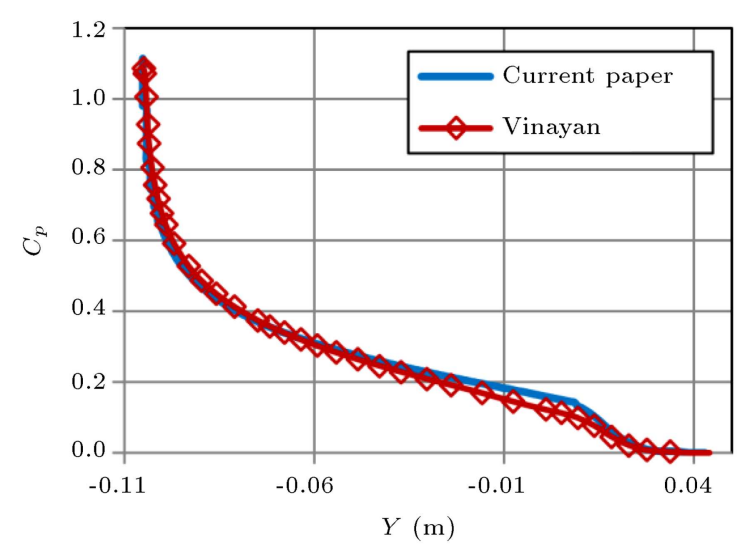

(c)

Figure 8. (a) Cox wedge geometry [15]. (b) Comparison of the computed free surface profile against the results of Cox experiment [15]. (c) Comparison of the computed $C_{p}$ against that of BEM model by Vinayan and Kinnas [14]. 


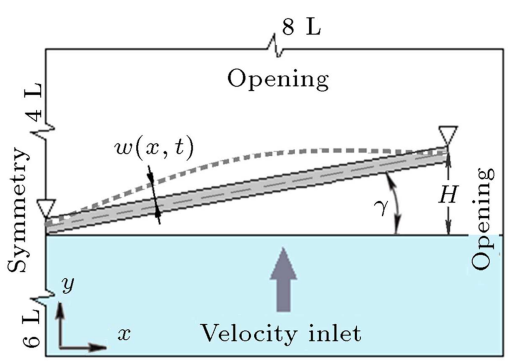

(a)

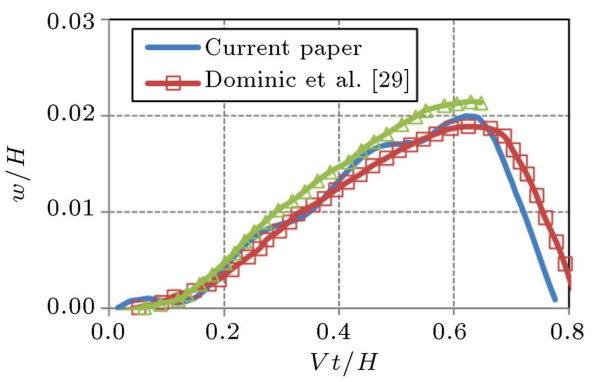

(b)

Figure 9. (a) The wedge's geometry and domain boundary conditions. (b) Comparison of the obtained normal deformation at the middle of the beam with results of Dominic et al. [29] and Korobkin et al. [27].

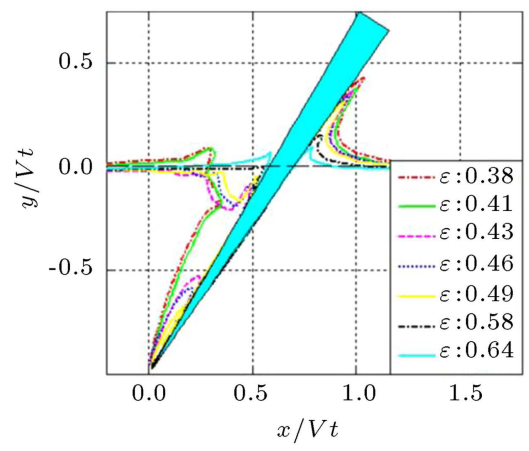

(a)

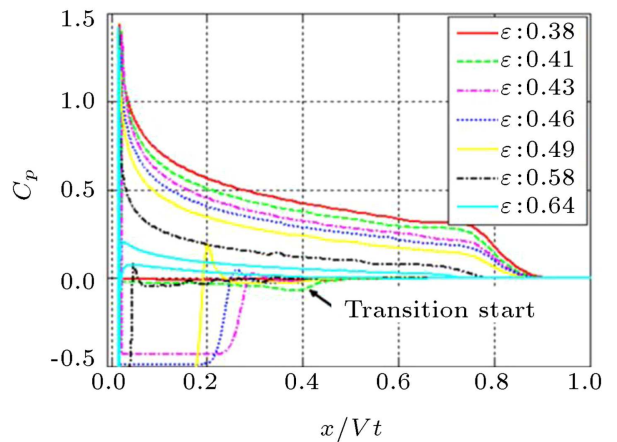

(b)

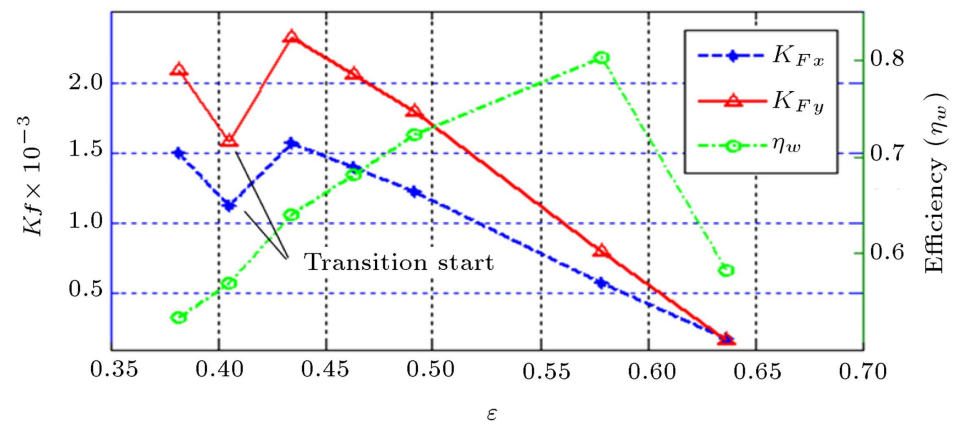

(c)

Figure 10. (a) Free surface patterns, (b) pressure distribution, and (c) performance curves at Fr $=6, e=0$ and $V t=0.076 \mathrm{~m}$.

\section{Results and discussion}

This section is organized in three distinct subsections. The first subsection focuses on the hydrodynamic characteristics of the rigid SP hydrofoil. The second subsection concentrates on the evaluation of structural flexibility effects on the transition condition. The last subsection deals with the effects of elasticity on the SP hydrofoil water entry performance curves. In doing so, the required parameters for the targeted analyses are displayed in Table 2.

\subsection{Hydrodynamic characteristics of the rigid SP hydrofoil}

To understand the effect of elasticity on the water entry characteristics of SP hydrofoil, its performance
Table 2. Parameter setting for the performed analyses.

\begin{tabular}{lc}
\hline \multicolumn{1}{c}{ Parameter } & Value \\
\hline Advance coefficient & 0.66 to 1.1 \\
Velocity ratio & 0.38 to 0.64 \\
Froude number & 4,6 \\
Elasticity factor & $0,1.2,4$ \\
\hline
\end{tabular}

in rigid body condition $(E=\infty)$ is presented in this subsection. The elasticity factor, $e=E s / E$, is hereby assumed to be 0 . The obtained results of pressure distributions, and free surface patterns in dimensionless coordinates $(x / V t$ and $y / V t)$ for water entering depth of $V t=0.076 \mathrm{~m}$ are illustrated in Figures 10(a) and (b). The performance curves which show the variation of dimensionless forces $\left(F_{x}\right.$, and $\left.F_{y}\right)$ and water entry 


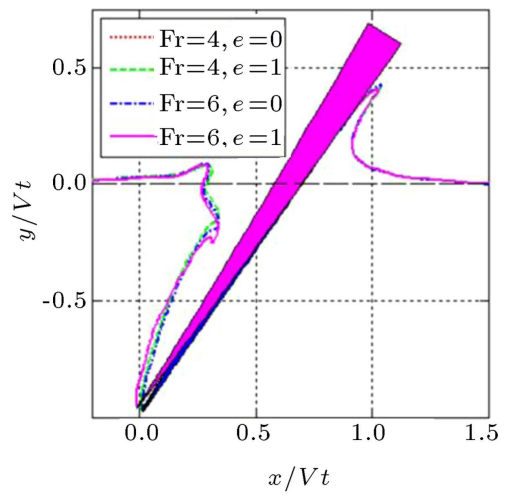

(a)

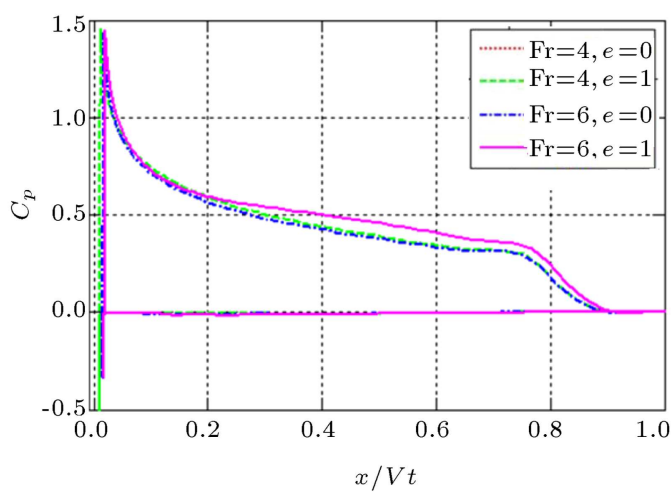

(b)

Figure 11. (a) Free surface patterns and (b) pressure distribution at Fr $=4$ and $6, \varepsilon=0.38, e=0$, and 1 , and $V t=0.076 \mathrm{~m}$.

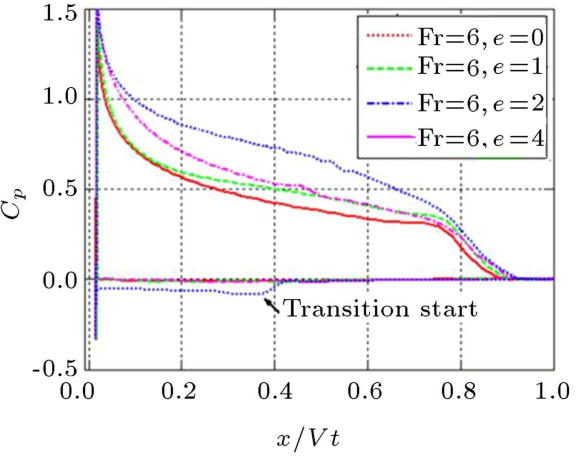

(a)

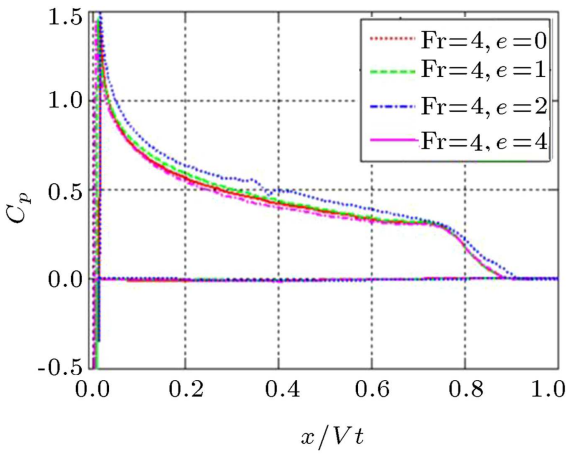

(b)

Figure 12. (a) Pressure distribution at $\mathrm{Fr}=6, \varepsilon=0.38, e=0-4$, and $V t=0.076 \mathrm{~m}$. (b) Pressure distribution at Fr $=$ $4, \varepsilon=0.38, e=0-4$, and $V t=0.076 \mathrm{~m}$.

efficiency (mentioned in Eqs. (21) and (22)) related to the variation of velocity ratio of $(\varepsilon=U / V)$ are presented in Figure 10(c).

Comparisons of the characteristic curves in Figure 10(c) and propeller schematic curves in Figure 3 show that the trends of dimensionless forces and efficiency for both SPP and simplified SP hydrofoils are favorably similar. Furthermore, the obtained free surface profiles and pressure distribution curves (Figure 10(a), and (b)) indicate that the transition condition starts at velocity ratio of $\varepsilon=0.41$. Therefore, the velocity ratio of $\varepsilon=0.38$ is located near the end of the fully ventilated condition.

\subsection{Effect of elasticity on transition condition} As previously pointed out in Section 3.2, when ventilated cavity impacts the hydrofoil side, transition condition occurs. Based on Olofsson's experiment [5], for $\mathrm{Fr}>3$, the start point of transition only depends on deadrise angle and velocity ratio. Therefore, in the presence of hydrofoil elasticity, the dependency of the start of transition on Froude number and elasticity factor should also be studied, again. In this subsection, hydrodynamic characteristics of elastic hydrofoil for velocity ratio of $\varepsilon=0.38$ corresponding to the end of a fully ventilated condition are investigated. The free surface profile and pressure distribution for elasticity factor, $e=0,1,2,4, \operatorname{Fr}=4,6$, are illustrated in Figures 11 and 12. Meanwhile, the hydrodynamic efficiencies and foil's leading edge deflection for the mentioned elasticity factors and Froude numbers are illustrated in Figures 13 to 15 .

As evident in Figure 11(a) and (b), the free surface profile and pressure distribution for rigid hydrofoil at $\mathrm{Fr}=4$ and 6 are absolutely identical, which is expected for Fr $>3$. Subsequently, FSI simulation is conducted and the hydrofoil material is assumed to be steel $(e=1)$. The obtained free surface patterns and pressure distributions for both $\mathrm{Fr}=4$ and $\mathrm{Fr}=6$, and material type $e=0$ and 1 are presented in Figure 11. Based on the results of elastic hydrofoil at $\mathrm{Fr}=4$, the similarity still exists with rigid condition. However, for $\mathrm{Fr}=6$, this similarity diminishes. This is due to the increase in the foil deflection at higher Froude number, which weakens the geometric similarity. Furthermore, from the pressure curve corresponding to $\mathrm{Fr}=6$ and $e=1$, it can be realized that through the increase of the foil deflection, the local pitch angle rises and, consequently, $C_{P}$ on the pressure side of the foil increases.

If the hydrofoil flexibility increases from $e=1$ to 


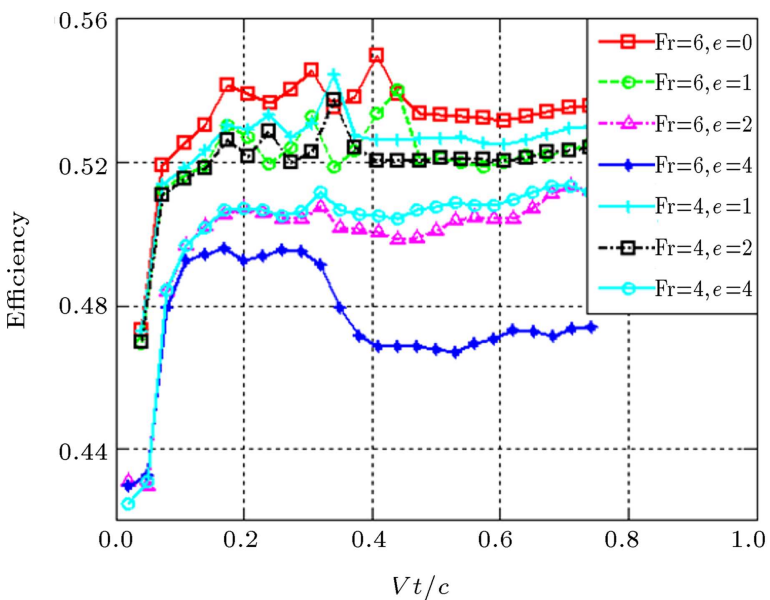

(a)

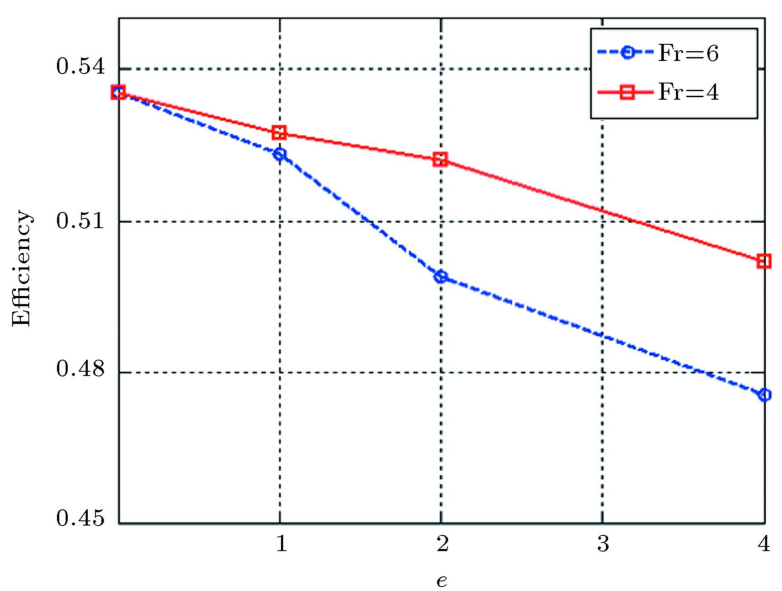

(b)

Figure 13. (a) Water entry efficiency versus time. (b) Water entry efficiency versus elasticity factor at Fr $=4,6$, and $\varepsilon=0.38$.

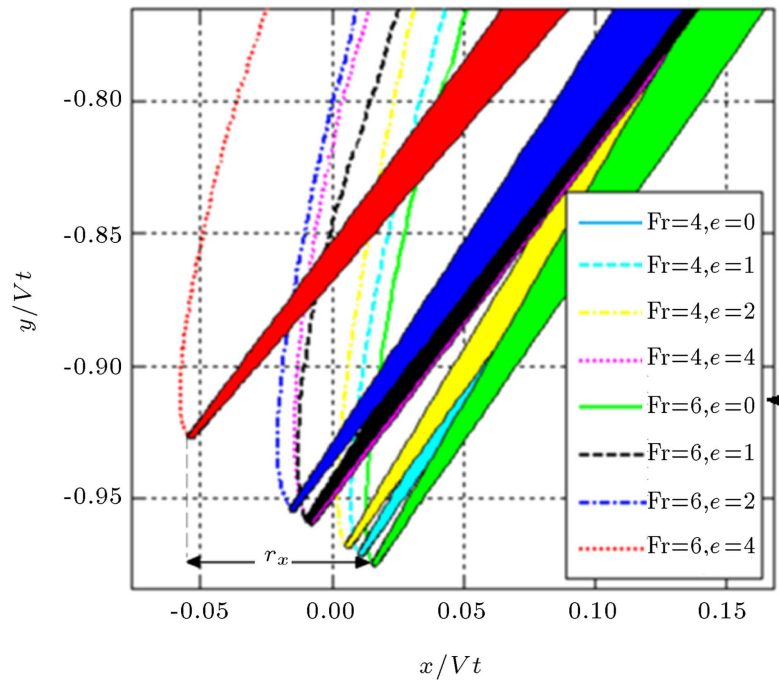

(a)

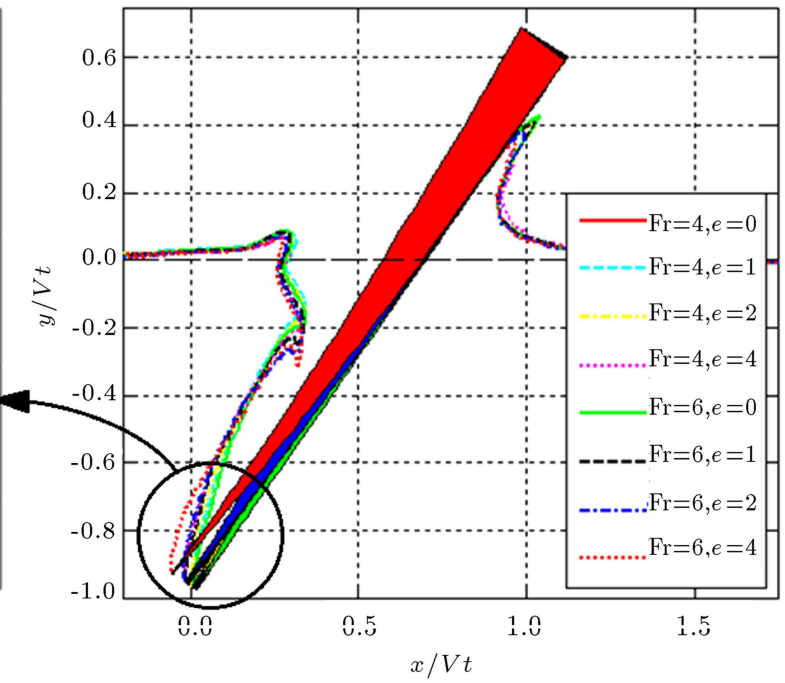

(b)

Figure 14. Foil deflection at $\operatorname{Fr}=4,6$, and $\varepsilon=0.38, e=0-4$, and $V t=0.076 \mathrm{~m}$.

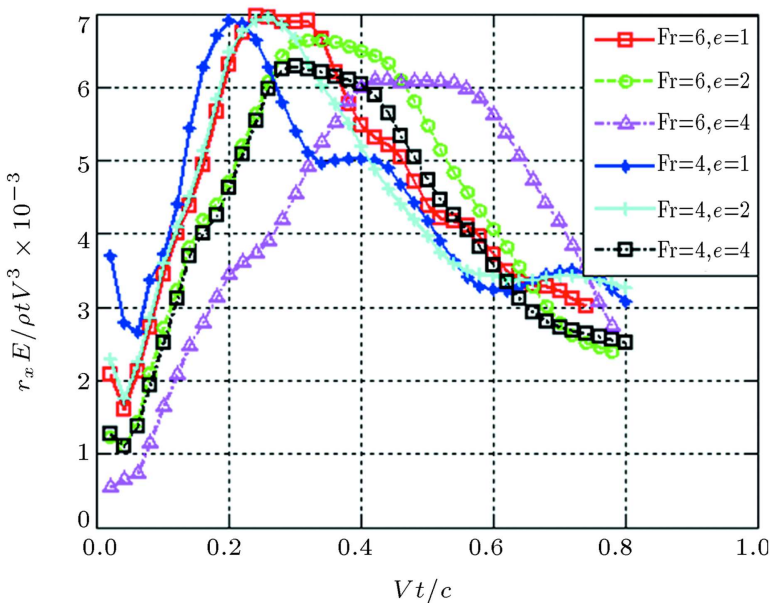

(a)

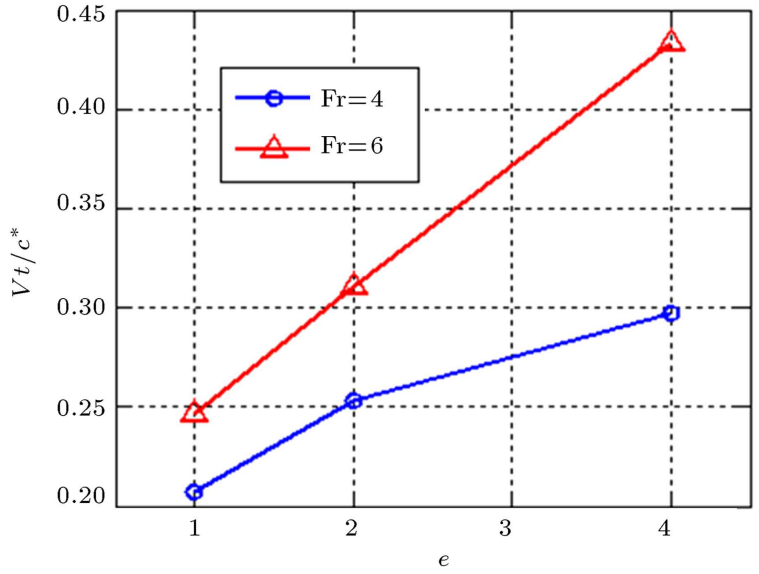

(b)

Figure 15. (a) Overshoot time versus elasticity factor and (b) dimensionless leading edge deflection versus elasticity factor at $\operatorname{Fr}=4,6, \varepsilon=0.38$, and $e=1-4$. 
$e=4$, the similarity of the results decreases further, and for $\mathrm{Fr}=6$ and $e=4$, the operational condition changes from fully ventilated to the transition condition (Figure 12(a)). This implies that flexibility of the foil structure can even change the operation condition of the water entry regime. However, the operational conditions for $\mathrm{Fr}=4$ are the same for all the considered elasticity factors (Figure 12(b)). Therefore, at elasticity factor $e=4$, there exist two different operational conditions for two Froude numbers greater than 3.

The hydrodynamic efficiency during the dimensionless water entering time $(V t / c)$ presented in Figure 13(a) shows the overall reduction due to the increase of elasticity factor and Froude number. This is due to the fact that energy required to deflect the foil structure during the time of water entry is extracted from the fluid flow energy. Thus, during the structural deflection, fluid flow loses part of its momentum, meaning that the case with greater elasticity factor and Froude number has more efficiency drop (Figure 13(b)).

Leading edge deflections shown in Figure 14 imply that the effect of Froude number on this parameter is more noticeable than the elasticity factor; this is due the fact that the force acting on the foil during the time of water entry time is proportional to $\mathrm{Fr}^{3}$, while the elasticity factor has a linear relation with $r_{x}$. If the leading edge dimensionless deflection is plotted during dimensionless water entry time $(V t / c)$, the curves in Figure 15(a) are obtained.

Dimensionless overshoot time $\left(V t / c^{*}\right)$ represents the hydroelastic characteristics parameter of a water entering object. This parameter shows the water entry depth at which the maximum dimensionless deflection $\left(r^{*}\right)$ occurs (Figure 15(a)). Also $V t / c^{*}$ is the function of the structure mass and flexibility. Figure 15(b) shows the variation of this parameter against elasticity factor for two investigated Froude numbers. As expected, the increase of the structural elasticity causes an increase in the overshoot time and its corresponding entering depth. However, an increase in Froude number and, consequently, the impact velocity will cause an increase in this parameter, too. This is due to an increase in the added mass based on Eq. (23) in the higher impact velocity.

\subsection{Effects of elasticity on SP hydrofoil water entry performance curves}

In this subsection, the effects of elasticity on hydrofoil performance curves are evaluated. To this end, the flexible SP hydrofoil with elasticity factor $e=1$ to 4 , for the velocity ratio range of $\varepsilon=0.38$ to 0.64 corresponding to fully ventilated, transition, and partially cavitated conditions, impacts the calm waterfree surface. The obtained free surface profiles and pressure distribution for elasticity factor $e=1$ and 4 are illustrated in Figures 16 and 17. Later on, the leading edge displacement curves during the waterentering process for the mentioned velocity ratios are presented in Figure 18. Finally, the effects of elasticity on SP hydrofoil performance curves are evaluated based on the obtained results in Figure 19.

Based on the comparison of the free surface patterns in Figure 17 and their pressure distributions in Figure 16, through the reduction of hydrofoil vertical velocity, $V$, (increase of $\varepsilon$ ) regardless of elasticity factor, the trends of pressure curves become more similar to the rigid body condition; hence, the effect of the foil flexibility diminishes. Based on the free surface patterns in Figure 17, the reduction of vertical velocity, (increase in $\varepsilon$ ) reduces the structural deflection, too.

Similar to Figure 15(a) in Subsection 6.2, Figure 18 presents the dimensionless displacement of the leading edge through the dimensionless time for elasticity factors of 1 and 4 and velocity ratio of $\varepsilon=0.38$ to 0.64 .

The comparison of these two groups of curves in Figure 18 shows that the dimensionless overshoot time $\left(V t / c^{*}\right)$, for the group curves of $e=4$, is evidently greater than that belonging to $e=1$. This means that velocity ratio variation does not affect $V t / c^{*}$ as much as the elasticity factor does. Hence, the effect of elasticity factor on $V t / c^{*}$ is more considerable than the velocity ratio is.

Similar to the rigid condition, the performance

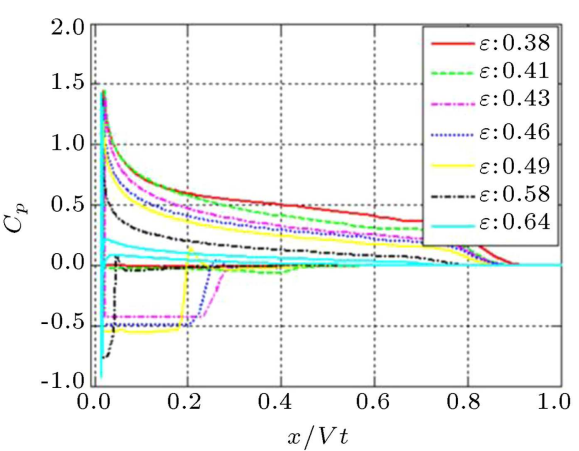

(a)

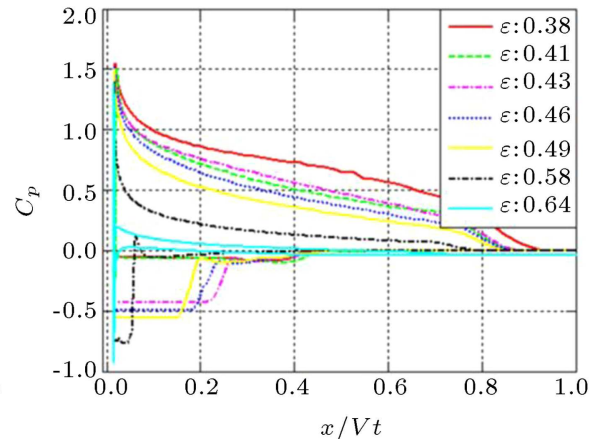

(b)

Figure 16. Pressure distributions at $\operatorname{Fr}=6$ and $\varepsilon=0.38-0.64$ : (a) $e=1$ and (b) $e=4$. 


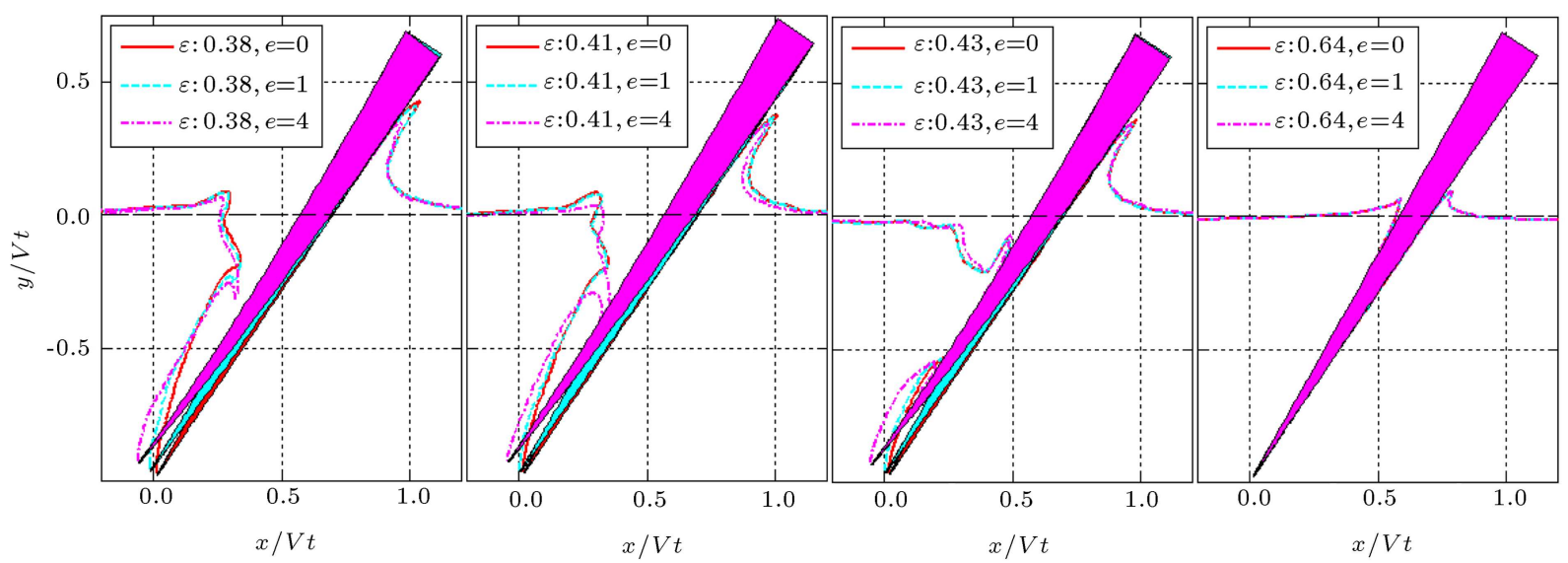

Figure 17. Free surface pattern and foil deflection at $\operatorname{Fr}=6, \varepsilon=0.38-0.64$, and $e=0,1,4$.

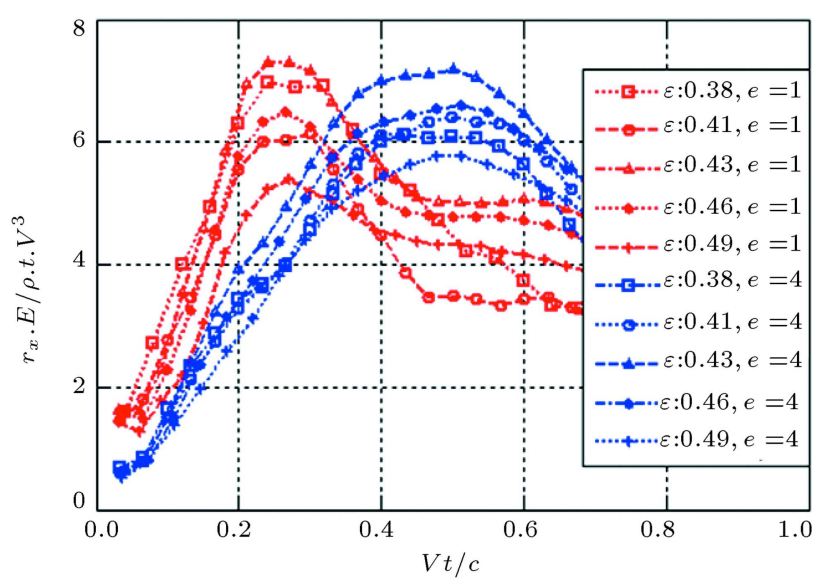

Figure 18. Dimensionless leading edge deflection versus time at $\mathrm{Fr}=6, \varepsilon=0.38-0.49$, and $e=1,4$.

curves of the elastic hydrofoil for the elasticity factors of 1, 2, and 4 are sketched in Figure 19(a). The comparison of the dimensionless forces shows that an increase in the foil flexibility causes a general growth in $K_{F y}$ and $K_{F x}$. It was pointed out earlier that an increase in foil flexibility and deflection causes an increase in the hydrofoil local pitch angle $(\phi)$. As a result, $C_{P}$ on the pressure side of the foil and the resultant force increase, too. However, the structural flexibility has stronger effect on the sensitive parts of the performance curve. The location of the transition point of the performance curve is highly dependent on the geometric and kinematic characteristics of the SP foil. Therefore, a geometrical variation due to the structural deflection can strongly affect this operational condition. As shown in Subsection 6.2, an increase in foil flexibility to $e=4$ moves the transition point toward the fully ventilated region. Shifting the transition regime on performance curve to the left can be observed in Figure 19(a) for $e=4$ and $\mathrm{Fr}=6$.

The obtained efficiency curves versus velocity ratio for the elasticity factors of 1,2, and 4 are presented in Figure 19(b). The general efficiency decline due to the increase in foil flexibility and deflection can be observed in this figure. The amount of efficiency lost by an increase in the structural elasticity in comparison with the rigid body condition is depicted in Figure 19(c). As previously declared, in an elastic water impact problem, the fluid energy wastes to deform the structure and, therefore, the water entry efficiency reduces. However, at high velocity ratios, the low resultant forces and insignificant deformations diminish the elasticity effects.

\section{Conclusions}

In this paper, hydroelastic behavior of a surface piercing hydrofoil was analyzed by a two-way coupled numerical method. The problem was investigated for a multi-phase domain containing water, vapor, and air. The coupled URANS equation, VOF scheme, and Zwart's cavitation model [31] were utilized to conduct the fluid simulation, while the linear elastic equations were used for structural simulation purposes. The investigated SP hydrofoil has a left deadrise angle of $55^{\circ}$ and a right deadrise angle of $120.2^{\circ}$. 0.7 million cells were considered for the fluid part, while 10,000 cells were used for the structural part, and displacementstep was assumed $0.1 \mathrm{~mm}$ in the conducted simulation. Results of Korobkin simulation [27] and Dominic and Maki numerical simulation [29] were utilized to validate the elastic water entry simulation. Favorable accordance was observed between the obtained results and the published data.

Subsequently, elastic water entry process of the SP hydrofoil was investigated for a particular range of velocity ratios and for specific Froude numbers. The effect of hydrofoil flexibility on the flow was analyzed and free surface profile and pressure distribution on both sides of the foil were extracted for different elasticity factors and Froude numbers. Similar to the propeller characteristic curves, the non-dimensional forces and efficiency curves of the rigid and elastic 


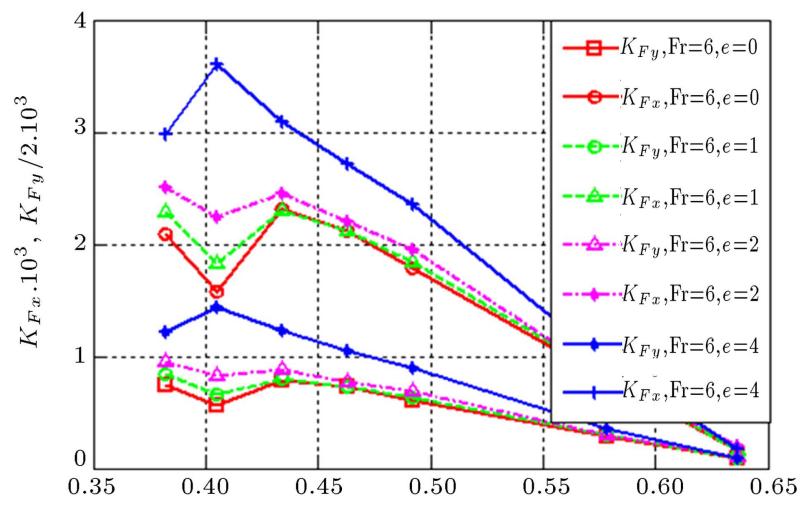

(a)

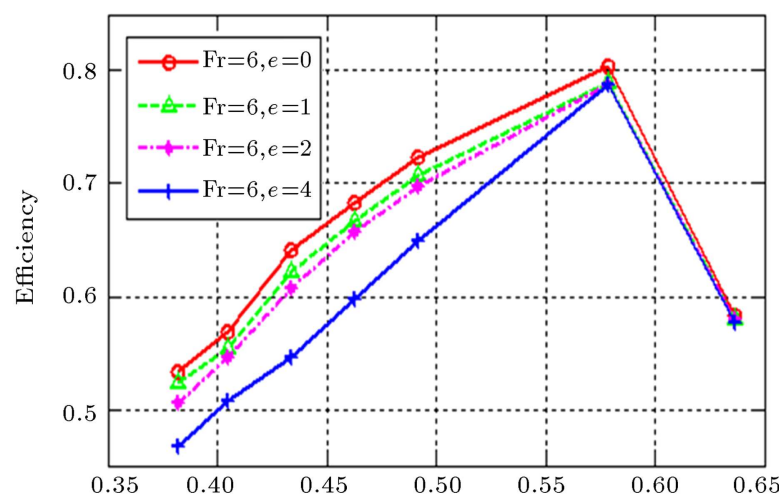

(b)

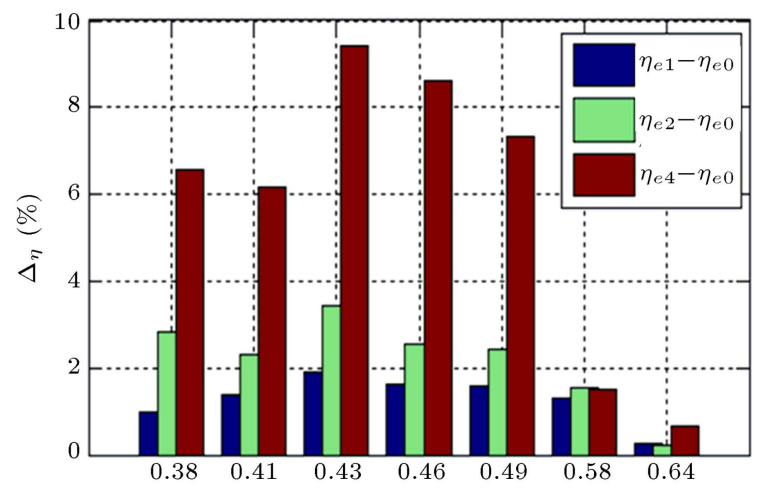

(c)

Figure 19. (a) Performance curves, (b) water entry efficiencies, and (c) efficiencies loses at $\operatorname{Fr}=6, e=0-4$, and $V t=0.076 \mathrm{~m}$.

foils were presented. Furthermore, a comparison of the characteristic curves for four different elasticity factors was made to examine the effect of elasticity on the ventilation regime, dimensionless force, and the defined wedge water entry efficiency.

Based on the obtained results for all the conducted simulations, one may conclude that the following findings are the important contributions of the current paper:

(a) For the first time, similar to SPP characteristic curves approach, dimensionless forces and efficiency curves are defined and presented for the wedge water entry. Based on the rigid wedge results of oblique thin wedge water entry simulation, three types of SPP ventilation patterns of fully ventilated, transition, and partially cavitated conditions were extracted. Moreover, the obtained performance curves of the wedge water entry have the same trend as the SPP characteristic curves do;

(b) Investigation of elastic water entry process of the SP hydrofoil for a particular range of velocity ratios and specific Froude numbers showed that, in the presence of elasticity and foil deflection, hydrodynamic similarity diminishes and the increase in elasticity can affect the ventilation regime pattern such as shifting of the transition start regime toward a fully ventilated zone;

(c) The comparison of the characteristic curves illustrates that, contrary to the flexible NACA foil propeller, an increase in foil elasticity and deflection increases the pitch angle and wedge load, hence decreasing the defined water entry efficiency;

(d) Ultimately, the variation of Froude number is shown to have stronger effect on the structural deflection than the elasticity factor.

Any future research may involve studying the hydroelastic analysis of an actual surface piercing propeller. This study may become instrumental in better understanding the challenges of a propeller structural design.

\section{Nomenclature}

\section{Independent variables}

$D \quad$ Propeller diameter (m)

$\beta \quad$ Wedge deadrise Angle $\left(^{\circ}\right)$ 


$\begin{array}{ll}\phi & \text { Foil pitch angle }\left(^{\circ}\right) \\ n & \text { Shaft rotational speed }(1 / \mathrm{s}) \\ U & \text { Inlet flow velocity }(\mathrm{m} / \mathrm{s}) \\ V & \text { Wedge vertical velocity }(\mathrm{m} / \mathrm{s}) \\ \varepsilon & \text { Velocity ratio }(-) \\ J & \text { Advance coefficient }(-) \\ F r & \text { Froude number }(-) \\ \sigma_{n} & \text { Cavitation number }(-) \\ E & \text { Material elasticity modulus }(\mathrm{GPa}) \\ e & \text { Elasticity factor }(-) \\ v & \text { Fluid velocity vector }(\mathrm{m} / \mathrm{s})\end{array}$

\section{Dependent variables}

$\begin{array}{ll}K_{F} & \text { Dimensionless force }(-) \\ \eta_{\text {wedge }} & \text { Wedge efficiency }(-) \\ r & \text { Structural deflection }(\mathrm{m}) \\ t^{*} & \text { Dimensionless overshoot } \\ \dot{m} & \text { Mass transfer rate }(\mathrm{kg} / \mathrm{s}) \\ m^{\prime} & \text { Added mass }(\mathrm{kg} / \mathrm{m})\end{array}$

\section{Physical parameters}

$\begin{array}{ll}\rho & \text { density }\left(\mathrm{kg} / \mathrm{m}^{3}\right) \\ \mu & \text { viscosity }(\mathrm{kg} / \mathrm{ms}) \\ P_{v} & \text { Saturated vapor pressure }(\mathrm{Pa}) \\ P_{a} & \text { Ambient pressure }(\mathrm{Pa})\end{array}$

\section{References}

1. Hadler, J.B. and Hecker, R. "Performance of partially submerged propellers", Proc 7th ONR Symposium on Naval Hydrodynamics, Rome, Italy (1968).

2. Hecker, R. "Experimental performance of a partially submerged propeller in inclined Flow", SNAME Spring Meeting, Lake Buena Vista, Florida, USA (1973).

3. Brandt, H. "Modellversuche mit schiffspropellern an der wasseroberfiache", Schiff und Hafen, 25(5), pp. 415-422 (1973).

4. Olofsson, N. "A contribution on the performance of partially submerged propellers", Proc FAST '93, 2nd Intl Conf on Fast Sea Transportation, Yokohama, Japan, 1, pp. 765-776 (1993).

5. Olofsson, N. "Force and flow characteristics of a partially submerged propeller", PhD Thesis, Department of Naval Architecture and Ocean Engineering, Chalmers Univ, Gotborg, Sweden (1996).

6. Young, Y.L. "Numerical modeling of supercavitating and surface-piercing propellers", PhD Thesis, Ocean Engineering Group, Department of Civil, University of Texas at Austin, Austin, TX, USA (2002).

7. Young, Y.L. and Kinnas, S.A. "Analysis of supercavitating and surface-piercing propeller flows via BEM", J. Computational Mechanics, 32, pp. 269-280 (2003).
8. Young, Y.L. "Fluid-structure interaction analysis of flexible composite marine propellers" , Journal of Fluids and Structures, 24, pp. 799-818 (2008).

9. Young, Y.L. and Savander, B.R. "Numerical analysis of large-scale surface-piercing propellers", Journal Ocean Engineering, 38(13), pp. 1368-1381 (May 2011).

10. Javanmardi, N. and Ghadimi, P. "Hydroelastic analysis of a semi submerged propeller using simultaneous solution of Reynolds averaged Navier-Stokes equations and linear elasticity equations", Journal of Engineering for Maritime Environment, 232(2), pp. 199-211 (2017). DOI: $10.1177 / 1475090217691864$

11. Wagner, H. "Uber stoss-und gleitvergange an der oberflache von flussigkeiten", Zeitschrift fur Angewandte Mathematik und Mechanik, 12, pp. 193-215 (1932).

12. Von Karman, T., The Impact of Seaplane Floats During Landing, NACA TN 321 (1929).

13. Yim, B. "Linear theory on water entry and exit problems of a ventilating thin wedge", J. Ship Res., 18(1), pp. 1-11 (1974).

14. Vinayan, V. and Kinnas, S.A. "A numerical nonlinear analysis of two-dimensional ventilating entry of surface-piercing hydrofoils with effects of gravity", $J$. Fluid Mech, 658, pp. 383-408 (2010).

15. Cox, B.D. "Hydrofoil theory for vertical water entry", PhD Thesis, Massachusetts Institute of Technology, Cambridge, MA, USA (1971).

16. Ghadimi, P., Dashtimanesh, A., and Djeddi, S.R. "Study of water entry of circular cylinder by using analytical and numerical solutions", J. Brazilian Society of Mech. Sci. Eng., 37(3), pp. 821-835 (2012).

17. Ghadimi, P., Feizi Chekab, M.A., and Dashtimanesh, A.A. "Numerical investigation of the water impact of an arbitrary bow section", ISH Journal of Hydraulic Engineering, http://dx.doi.org/10.1080/ 09715010.2013.796690, pp. 1-10 (2013).

18. Ghadimi, P., Feizi Chekab, M.A., and Dashtimanesh, A. "Numerical simulation of water entry of different arbitrary bow sections", J. Naval Archit Marine Eng., 11(2), pp. 117-129 (2014).

19. Ghadimi, P., Saadatkhah, A., and Dashtimanesh, A. "Analytical solution of wedge water entry by using Schwartz-Christoffel conformal mapping", Int. J. Modeling, Simulation and Scientific Computing, 2(3), pp. 337-354 (2011).

20. Farsi, M. and Ghadimi, P. "Finding the best combination of numerical schemes for 2D SPH simulation of wedge water entry for a wide range of deadrise angles", Int. J. Naval Archit Ocean Eng., 6, pp. 638651 (2014a).

21. Farsi, M. and Ghadimi, P. "Effect of flat deck on catamaran water entry through smoothed particle hydrodynamics", Institution of Mechanical Engineering Part $M: J$ Engineering for the Maritime Environment, 230(2), pp. 267-280 (2016). DIO: $10.1177 / 1475090214563960$ 
22. Farsi, M. and Ghadimi, P. "Simulation of 2D symmetry and asymmetry wedge water entry by smoothed particle hydrodynamics method", J. Brazilian Society of Mech. Sci. Eng., 37(3), pp. 821-835 (2015).

23. Feizi Chekab, M.A., Ghadimi, P., and Farsi, M. "Investigation of three-dimensionality effects on aspect ratio on water impact of $3 \mathrm{D}$ objects using smoothed particle hydrodynamics method", J Brazilian Soc Mech Sci Eng, 38(7) (June 2015). DOI: 10.1007/s40430-015$0367-8$

24. Faltinsen, O.M. and Semenov, Y.A. "Nonlinear problem of flat-plate entry into an incompressible liquid", J. Fluid Mech, 611, pp. 151-173 (2008).

25. Faltinsen, O.M. "Water entry of a wedge by hydroelastic orthotropic plate theory", Journal of Ship Research, 43(3), pp. 180-193, Sept. (1999).

26. Lu, C.H., He, Y.S., and Wu, G.X. "Coupled analysis of nonlinear interaction between fluid and structure during impact", Journal of Fluids and Structures, 14, pp. 127-146 (2000).

27. Korobkin, A.A., Gueret, R., and Malenica, S. "Hydroelastic coupling of beam finite element model with Wagner theory of water impact", Journal of Fluids and Structures, 22, pp. 493-504 (2006).

28. Maki, K.J., Lee, D., Troesch, A.W., and Vlahopoulos, N. "Hydroelastic impact of a wedge-shaped body", Ocean Engineering, 38, pp. 621-629 (2011).

29. Dominic, J., Piro, N., Kevin, J., Maki, K.J. "Hydroelastic analysis of bodies that enter and exit water", Journal of Fluids and Structures, 37, pp. 134-150 (2013).

30. Bagheria, M.R., Seif, M.S., Mehdigholia, H., and Yaakobb, O. "Analysis of hydrodynamics and noise prediction of the marine propellers under cavitating and non-cavitating conditions", Scientia Iranica B., 22(5), pp. 1918-1930 (2015).

31. Zwart, P., Gerber, A.G., and Belamri, T. "A two-phase model for predicting cavitation dynamics", ICMF International Conference on Multiphase Flow, Yokohama, Japan (2004).

32. Ji, B., Luo, X.W., Wang, X., Eng, X.X., Wu, Y.L., and $\mathrm{Xu}, \mathrm{H}$.Y. "Unsteady numerical simulation of cavitating turbulent flow around a highly skewed model marine propeller", J. Fluids Eng.-Trans, ASME., 133(1), 011102 (2011).
33. Mejri, I., Bakir, F., Rey, R., and Belamri, T. "Comparison of computational results obtained from a homogeneous cavitation model with experimental investigations of three inducers", J. Fluids Eng.-Trans. ASME., 128, pp. 1308-1323 (2006).

34. Newmark, N.M. "Method of computation for structural dynamics", ASCE Journal of Engineering Mechanics Division, 85, pp. 67-94 (1959).

35. Shademani, R. and Ghadimi, P. "Numerical assessment of turbulence effect on forces, spray parameters, and secondary impact in wedge water entry problem using k- $\varepsilon$ method", Scientia Iranica, 24(1), pp. 223236 (February 2017). DOI: 10.24200/SCI.2017.4028

36. Ghadimi, P., Djeddi, S.R., Oloumiyazdi, M.H., and Dashtimanesh, A. "Simulation of flow over a confined square cylinder and optimal passive control of vortex shedding using a detached splitter plate ponditions", Scientia Iranica B, 22(1), pp. 175-186 (2015).

37. https://www.sharcnet.ca/Software/Ansys (2016).

\section{Biographies}

Nasrin Javanmardi received her BS and MS degrees in Marine Engineering and Naval Architecture from Sharif University of Technology in 2005 and 2008, respectively. She was then admitted to the $\mathrm{PhD}$ program at Amirkabir University in the Department of Marine Technology in 2015 and is currently working on her dissertation. Her main research interests include hydrodynamics and hydroelastics of surface piercing propellers, and she has authored several articles on these topics.

Parviz Ghadimi received his $\mathrm{PhD}$ degree in Mechanical Engineering in 1994 from Duke University, USA. He served one year as a Research Assistant Professor at Mechanical Engineering Department and six years as a Visiting Assistant Professor at Mathematics Department in Duke. He then joined the Department of Marine Technology at Amirkabir University of Technology, Iran in Fall 2005. He is currently a Full Professor of Hydromechanics at that department. His main research interests include hydrodynamics, hydroacoustics, thermo-hydrodynamics, and CFD, and he has authored over one hundred scientific papers in these fields. 